\title{
Pilot study of WT1 peptide-pulsed dendritic cell vaccination with docetaxel in esophageal cancer
}

\author{
TATSUO MATSUDA $^{1}$, HIROYA TAKEUCHI ${ }^{1,2}$, TOSHIHARU SAKURAI $^{3}$, SHUHEI MAYANAGI $^{1}$, \\ EISUKE BOOKA $^{1}$, TOMONOBU FUJITA ${ }^{3}$, HAJIME HIGUCHI ${ }^{4}$, JUNICHI TAGUCHI ${ }^{5}$, \\ YASUO HAMAMOTO $^{6}$, HIROMASA TAKAISHI ${ }^{6}$, HIROFUMI KAWAKUBO ${ }^{1}$, MASATO OKAMOTO $^{3}$, \\ MAKOTO SUNAMURA $^{7}$, YUTAKA KAWAKAMI ${ }^{3}$ and YUKO KITAGAWA $^{1}$
}

\begin{abstract}
${ }^{1}$ Department of Surgery, Keio University School of Medicine, Tokyo $160-8582 ;{ }^{2}$ Department of Surgery, Hamamatsu University School of Medicine, Hamamatsu, Shizuoka 431-3192; ${ }^{3}$ Division of Cellular Signaling, Institute for Advanced Medical Research, Keio University School of Medicine, Tokyo 160-8582; ${ }^{4}$ Department of Gastroenterological Chemotherapy, International University of Health and Welfare, Mita Hospital, Tokyo 108-8329; ${ }^{5}$ Tokyo Midtown Clinic, Midtown Tower 6F, Tokyo 107-6206; ${ }^{6}$ Keio Cancer Center, Keio University School of Medicine, Tokyo 160-8582; ${ }^{7}$ Department of

Digestive Tract Surgery and Transplantation Surgery, Hachioji Medical Center,

Tokyo Medical University, Tokyo 193-0998, Japan
\end{abstract}

Received January 31, 2017; Accepted May 4, 2018

DOI: $10.3892 / 01.2018 .8734$

\begin{abstract}
In the present study, the immune response to Wilms tumor gene 1 (WT1) peptide-pulsed dendritic cell (DC) vaccination combined with docetaxel (DCDOC) in advanced esophageal cancer patients who had already received first-line chemotherapy was investigated. Ten HLA-A*2402 patients were treated with docetaxel $\left(50 \mathrm{mg} / \mathrm{m}^{2}\right)$ on day 1 and WT1 peptide-pulsed DC vaccination ( $1 \times 10^{7}$ cells) on days 15 and 22 (repeated every 4 weeks for 3 cycles). The delayed-type hypersensitivity skin test, HLA tetramer assay and interferon- $\gamma$ enzyme-linked immunospot (ELISPOT) assay were used to evaluate the induction of a WT1-specific immune response. Median overall survival was 5 months (range, 1.1-11.6). The clinical effect of DCDOC therapy was not observed and only 1 patient could complete the protocol therapy. Disease progression was observed in 9 patients and 1 patient succumbed to fatality during the second cycle of therapy. As a pilot study, it was not possible to evaluate the safety of WT1 peptide-pulsed DCDOC therapy for esophageal squamous cell cancer. However, a WT1-specific response in 6 patients, as indicated by
\end{abstract}

Correspondence to: Dr Hiroya Takeuchi, Department of Surgery, Keio University School of Medicine, 35 Shinanomachi, Shinjuku-ku, Tokyo 160-8582, Japan

E-mail: htakeuchi@a6.keio.jp

Dr Yutaka Kawakami, Division of Cellular Signaling, Institute for Advanced Medical Research, Keio University School of Medicine, 35 Shinanomachi, Shinjuku-ku, Tokyo 160-8582, Japan

E-mail: yutakawa@z5.keio.jp

Key words: WT1, peptide, esophageal cancer, docetaxel, dendritic cell vaccination, immunotherapy the ELISPOT or HLA/WT1-tetramer assay, was demonstrated. The results suggested that the positive immune response had significant relevance on the low percentage of $\mathrm{CD} 11 \mathrm{~b}^{+}$and $\mathrm{CD}_{6} \mathrm{~b}^{+}$granulocytic myeloid-derived suppressor cells in $\mathrm{CD}^{+} 5^{+}$cells. Furthermore, DCDOC elicited a WT1-specific immune response regardless of the myelosuppression associated with docetaxel. The present findings support future studies and further work to assess DCDOC as an adjuvant therapy for esophageal cancer will be performed. The present clinical trial was registered in the University Hospital Medical Information Network (UMIN) Clinical Trials Registry on November 11th, 2011, no. UMIN000006704.

\section{Introduction}

Esophageal cancer is a common fatal cancer worldwide, often diagnosed at an advanced stage. Long-term outcomes remain poor despite advances in chemotherapy, indicating the need for new therapeutic targets to improve prognosis (1-3). Immunotherapy is an emerging treatment against cancer. Inhibition of immune-checkpoints using programmed death- 1 , programmed death ligand-1, and cytotoxic T-lymphocyte (CTL)-associated protein 4 antibodies appear to be promising immunotherapy approaches. However, the efficacy of immune-checkpoint inhibition is approximately $20 \%$ in solid cancer (4). Therefore, the development of other immunotherapy approaches such as vaccination remains a priority. Vaccination strategies involving dendritic cells (DCs)-important antigen-presenting cells for T-cell activation-have been developed. Antigen-pulsed autologous DCs have been applied for therapeutic cancer vaccination (5). An autologous DC vaccine stimulated with prostatic acid phosphatase and granulocyte-macrophage colony-stimulating factor (GM-CSF), recently approved by the United States Food and Drug Administration, has been shown to prolong overall survival of prostate cancer patients (6). 
The Wilms tumor gene 1 (WT1) antigen is a well-known cancer antigen expressed in many types of solid tumors and hematological malignancies (7). The WT1 protein has been reported to be overexpressed in $95 \%$ of esophageal cancer patients (8). A WT1 peptide vaccine has been tested in a variety of solid tumors $(9,10)$. In particular, the HLA-A*2402-restricted modified 9-mer WT1 peptide (CYTWNQMNL) stimulates WT1-specific CTLs more effectively than the natural 9-mer WT1 peptide (11). We previously conducted a pilot study of CYTWNQMNL-pulsed DC vaccination combined with gemcitabine (DCGEM) as the first-line therapy in chemotherapy-naive pancreatic cancer patients with local advancement or metastasis (12). We found the therapy to be feasible, tolerable, and effective as a first-line therapy for inducing antitumor T-cell responses in patients with advanced pancreatic cancer without liver metastases. Next, we planned a pilot study of WT1 peptide-pulsed DC vaccination therapy in esophageal cancer. A combination of 5-fluorouracil (5-FU) and cisplatin is presently used in Japan as first-line therapy, followed by docetaxel as second-line therapy (13). Single-agent docetaxel in patients with metastatic esophageal cancer revealed effectiveness in a phase II study; however, the response rate was low (20.7\%) (14). At the same time, the immune enhancement effect of docetaxel has been reported (15-17). Therefore, we planned a pilot study of WT1 peptide-pulsed DC vaccination combined with docetaxel (DCDOC) in advanced esophageal cancer patients who had already received first-line chemotherapy.

\section{Patients and methods}

Study design. Ten esophageal cancer patients were enrolled in the pilot study, which was performed at Tokyo Midtown Clinic (Tokyo, Japan) and Keio University (Tokyo, Japan). The primary endpoints were adverse events. Common Terminology Criteria for Adverse Events v4.0 was used to grade the adverse events. The secondary endpoints were immune response to the WT1 peptide, overall survival, and response rate. Response Evaluation Criteria in Solid Tumors (RECIST) (v1.1) was used to evaluate the clinical response (18). Overall survival was defined as the time between the date when informed consent was obtained and the date of death.

At the baseline, complete history examination, physical examination, computed tomography (CT), and laboratory tests were performed. The clinical stage of the tumors was determined according to the TNM classification of the International Union against Cancer. A repeat CT study was carried out before each cycle and at one month after the third cycle of treatment. Therapy was stopped when patients were diagnosed with disease progression.

The institutional review board of Keio University approved the study, and all patients provided written informed consent. This clinical trial was registered in the University Hospital Medical Information Network (UMIN) Clinical Trials Registry, no. UMIN-000007925.

Inclusion and exclusion criteria. Inclusion criteria were i) histological or cytological diagnosis of esophageal cancer (squamous cell carcinoma, adenocarcinoma, adenosquamous carcinoma); ii) unresectable esophageal cancer or recurrence after resection of esophageal cancer; iii) HLA-A*2402; iv) an Eastern Cooperative Oncology Group performance status of $0-2$; v) no immediate allergy to the WT1 peptide; vi) a measurable target lesion that could be evaluated according to RECIST; vii) a lesion refractory to treatment with first-line chemotherapy or chemoradiotherapy; and viii) adequate cardiac, hepatic, hematologic, and renal function. Exclusion criteria were i) tracheo-esophageal fistula; ii) symptom of brain metastasis; iii) other active primary malignancies; iv) history of allergic disease; v) severe comorbidity (cardiovascular disease, fibroid lung, infections, interstitial pneumonia, liver disease, renal disease, uncontrolled diabetes); vi) pericardial fluid or pleural effusion requiring treatment; vii) pregnant or nursing women; viii) men planning conception; ix) severe psychiatric disease; $x$ ) active autoimmune disease; $x i)$ current treatment with immunosuppressive agents; and xii) other reasons for unsuitability.

DC vaccine preparation and DCDOC. A detailed protocol for the preparation of the DC vaccine has been reported previously $(12,19)$. Isolated peripheral blood mononuclear cells (PBMCs) were incubated in plastic tissue culture plates in AIM-V medium (Gibco; Thermo Fisher Scientific, Inc., Waltham, MA, USA). After a 30-min incubation at $37^{\circ} \mathrm{C}$, non-adherent cells were washed, and adherent cells were placed in AIM-V containing interleukin 4 (IL-4; 50 ng/ml; Primmune Inc., Kobe, Japan) and GM-CSF (50 ng/ml; Primmune Inc.) to generate immature DCs. Five days after culture, OK-432 (10 $\mu \mathrm{g} / \mathrm{ml}$; Chugai Pharmaceutical Co., Ltd., Tokyo, Japan) and prostaglandin E2 (50 ng/ml; Daiichi Fine Chemical Co., Ltd., Toyama, Japan) were added to stimulate immature DCs for $24 \mathrm{~h}$. The generated DCs were pulsed with $100 \mu \mathrm{g}$ of WT1 peptide (NeoMPS, San Diego, CA, USA) for 1 h. HLA-DR ${ }^{+}, \mathrm{HLA}^{-A B C}{ }^{+}$

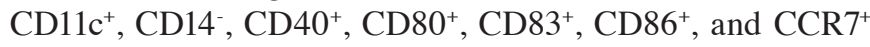
phenotypes were considered as indicating mature DCs (20). A fixed dose of $10^{7} \mathrm{WT} 1$ peptide-pulsed DCs was injected into the dermis close to the inguinal or axillary lymph nodes on days 15 and 22 . Docetaxel $\left(50 \mathrm{mg} / \mathrm{m}^{2}\right)$ was administered every 4 weeks by intravenous drip infusion on day 1 (Fig. 1). Docetaxel was administered before vaccination, because we expected immune enhancement effect of docetaxel (15-17). DC vaccination was repeated over 3 cycles in patients who were not diagnosed progressive disease. After termination or completion of the protocol therapy, post-protocol DC vaccination could continue with patients' consent. Dendritic cells were generated in the cell processing facility in Tokyo Midtown Clinic, headed by Dr. Junichi Taguchi.

Immunological monitoring. Peripheral blood was collected from patients on days 1 and 15 of each cycle and twice for 4 weeks after the third cycle (Fig. 1). We analyzed the PBMCs on day 1 of first cycle as pre-vaccination samples and PBMCs after day 1 of second cycle as post-vaccination samples. Immune response to the WT1 peptide was analyzed using the interferon (IFN)- $\gamma$ enzyme-linked immunospot (ELISPOT) assay, HLA tetramer staining assay, and delayed-type hypersensitivity (DTH) skin test (12).

DTH test. Induration diameters and erythema were measured $48 \mathrm{~h}$ after peptide injection on day 1 of each cycle and at 


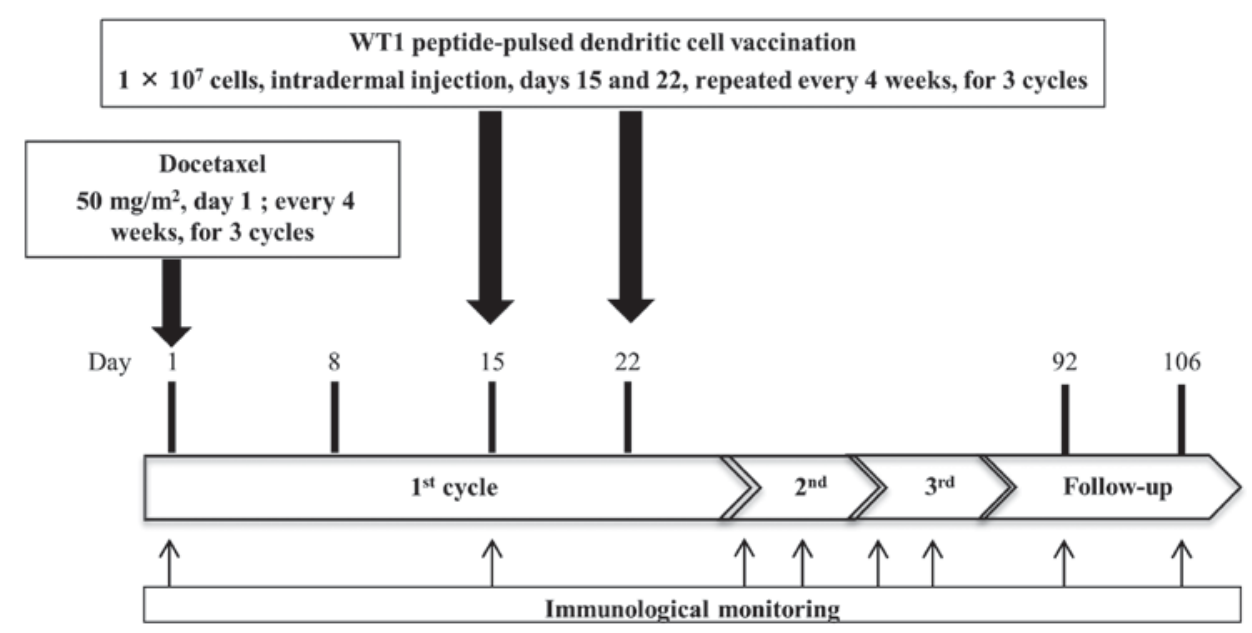

Figure 1. Protocol for DCDOC therapy. WT1 peptide-pulsed DCs (107 cells/injection) were injected into the dermis on days 15 and 22 every 4 weeks. Docetaxel $\left(50 \mathrm{mg} / \mathrm{m}^{2}\right)$ was administered on day 1 . DC vaccination was repeated over three cycles. Immunological monitoring was performed on days 1 and 15 of each cycle and 2 times at 4 weeks after the third cycle.

4 weeks after the third cycle. Erythema diameter $>5 \mathrm{~mm}$ was defined as a positive reaction.

In vitro generation of peptide cocktail-cultured PBMCs. After thawing cryopreserved PBMCs from patients, these were stimulated with $10 \mu \mathrm{g} / \mathrm{ml}$ modified-type WT1 peptide (CYTWNQMNL; Merck Bioscience AG, Läufelfingen, Switzerland) and $16 \mu \mathrm{g} / \mathrm{ml} \mathrm{CE}$ control peptide pool HLA-A 24 (8 peptides; Bio-Synthesis Inc., Lewisville, TX, USA) in AIM-V CTS medium (Gibco; Thermo Fisher Scientific, Inc.) supplemented with $10 \mathrm{ng} / \mathrm{ml} \mathrm{IL-7} \mathrm{(PeproTech,} \mathrm{Inc.,}$ Rocky Hill, NJ, USA), 20 U/ml IL-2 (Shionogi, Osaka, Japan), and 10\% human AB serum (MP Biomedicals, Solon, OH, USA). After 9 days of culture, cells were analyzed by the WT1-specific IFN- $\gamma$ ELISPOT assay and HLA tetramer assay (12).

WT1 peptide/HLA-A*2402 tetramer assay. HLA tetramers (T-Select MHC Tetramer; MBL: Medical and Biological Laboratories Co., Ltd., Nagoya, Japan) were used to access WT1-specific CD8 ${ }^{+}$T-cells in peripheral blood (21). Results were defined as positive when $\mathrm{CD} 3^{+}, \mathrm{CD} 8^{+}$, and WT1/HLA-A24 tetramer-positive cells were detected. We could not detect $\mathrm{CD}^{+}, \mathrm{CD}^{+}$, and HIV env/HLA-A24 tetramer-positive cells in the negative controls (12).

WT1-specific INF- $\gamma$ ELISPOT assay. PBMCs were defined as sensitized to WT1 peptide when the number of spots in response to the WT1 peptide was at least twice that in response to HIV env peptide-pulsed stimulator cells with the INF- $\gamma$ ELISPOT assay (22).

Cell surface marker analysis for phenotyping. PBMCs were incubated with each fluorescent-conjugated antibody for $45 \mathrm{~min}$ at $4^{\circ} \mathrm{C}$ in the dark. After washing with cell sorting buffer (phosphate-buffered saline with 2\% FBS), stabilizing fixative (BD Biosciences, San Jose, CA, USA) was used to fix the cells and these were analyzed by flow cytometry (Gallios; Beckman Coulter, Inc., Brea, CA, USA). FACS data were analyzed by Kaluza software (Beckman Coulter, Inc.).
Statistical analysis. Statistical analyses were conducted using SPSS software v21 (IBM Corporation, Armonk, NY, USA). The immune response was analyzed by t-test. $\mathrm{P}<0.05$ was considered to indicate a statistically significant difference.

\section{Results}

Patient characteristics. The patients' clinical characteristics are summarized in Table I. From January 2012 to January 2014, 25 patients received HLA typing. Twelve HLA-A*2402-positive patients were enrolled, 2 patients left the study before the treatment protocol was started. One patient hoped to undergo another treatment after providing consent. Another patient dropped out of this study owing to deterioration in renal function. The remaining 10 patients (2 with stage IV esophageal squamous cell cancer and 8 with recurrence of esophageal squamous cell cancer after surgery) had a median age of 60.5 years (range, $49-71$ years). All patients had squamous cell carcinoma. Five patients received only first-line chemotherapy; 1 patient, second-line; 3 patients, third-line; and 1 patient, fourth-line therapy. Seven patients had already received chemoradiotherapy.

The median overall survival was 5 months (range, 1.1-11.6). Only 1 patient completed the protocol therapy. Eight patients terminated the protocol treatment because of rapid disease progression. One patient (patient 7) died, probably from tumor bleeding, during therapy. Primary esophageal cancer invaded the aorta, and a large metastatic lymph node invaded the stomach wall directly. However, the exact cause of death is not confirmed because her family refused an autopsy. The remaining 5 patients received post-protocol DC vaccination after termination or completion of the protocol treatment. The median number of DC vaccine administration was 5 times (range, 2-9 times).

Adverse events. All adverse events information within the protocol treatment period is reported in Table II. There were no adverse skin reactions at the site of vaccination. Three patients had grade 4 neutropenia, and 1 patient had grade 3 febrile neutropenia. Grade 5 hypoxia occurred in patient 6 , for whom 


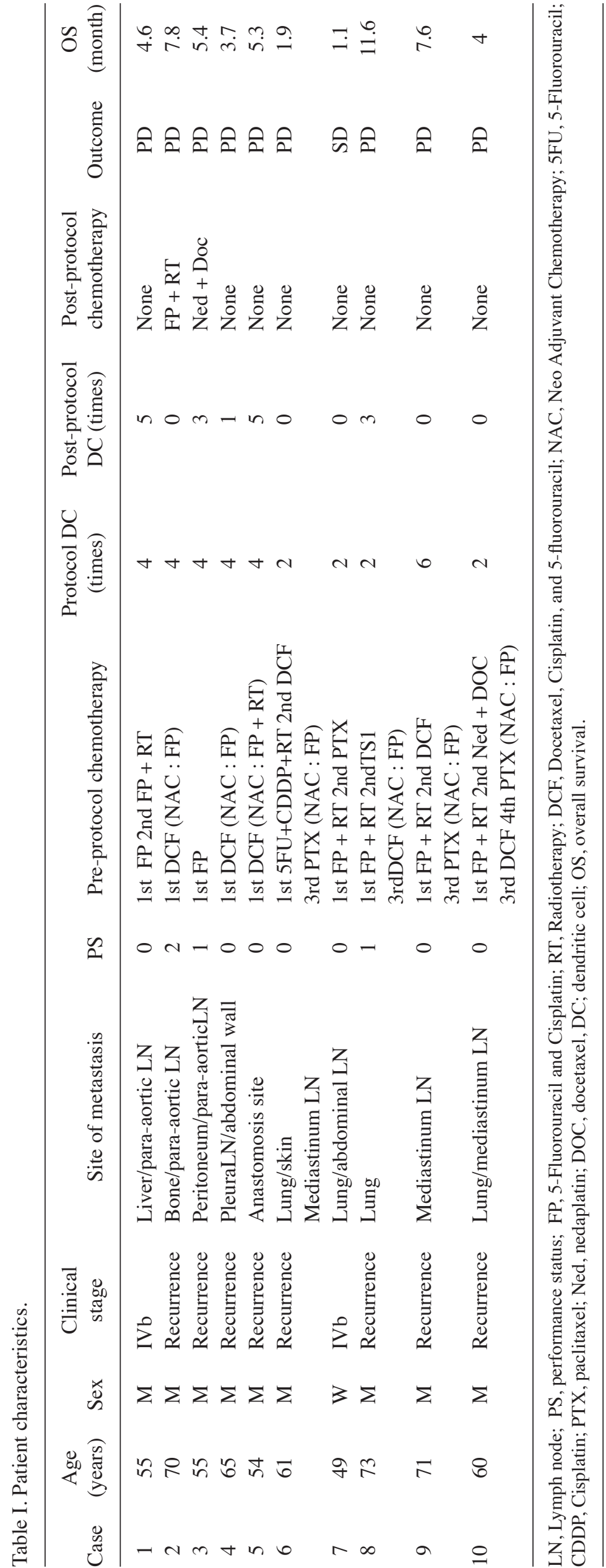


Table II. Adverse events.

\begin{tabular}{llllll}
\hline & \multicolumn{5}{c}{ Grade } \\
\cline { 2 - 6 } Adverse event & 1 & 2 & 3 & 4 & 5 \\
\hline A, Hematotoxicity & & & & & \\
\hline Febrile & 0 & 0 & 1 & 0 & 0 \\
Neutropenia & 0 & 2 & 2 & 3 & 0 \\
\hline
\end{tabular}

B, Non-hematotoxicity

Respiratory disorders

Pulmonary fistula

Hypoxia

Pleural effusion

Gastrointestinal disorders

\begin{tabular}{|c|c|c|c|c|}
\hline Nausea & 1 & 0 & 0 & 0 \\
\hline Constipation & 2 & 0 & 0 & 0 \\
\hline Ascites & 1 & 0 & 0 & 0 \\
\hline Mucositis oral & 1 & 0 & 0 & 0 \\
\hline Nervous system disorders & & & & \\
\hline Peripheral sensory neuropathy & 1 & 0 & 0 & 0 \\
\hline General disorders & & & & \\
\hline $\begin{array}{l}\text { Sudden death not } \\
\text { otherwise specified }\end{array}$ & 0 & 0 & 0 & 0 \\
\hline Fatigue & 2 & 1 & 0 & 0 \\
\hline Pain & 0 & 0 & 1 & 0 \\
\hline
\end{tabular}

Metabolism and

nutrition disorders

\begin{tabular}{llllll} 
Anorexia & 1 & 0 & 2 & 0 & 0 \\
Hypercalcemia & 0 & 0 & 1 & 0 & \\
$\begin{array}{l}\text { Musculoskeletal disorders } \\
\quad \text { Myalgia }\end{array}$ & 1 & 0 & 0 & 0 & 0 \\
$\begin{array}{l}\text { Skin and subcutaneous } \\
\text { tissue disorders } \\
\text { Alopecia }\end{array}$ & & & & & \\
\hline
\end{tabular}

Common Terminology Criteria for Adverse Events version 4.0 was used to grade the adverse events.

we stopped the protocol therapy because of disease progression after 1 course of therapy. One month after the protocol therapy was stopped, patient 6 died due to tracheal obstruction. Patient 7, who died during the protocol therapy as mentioned above, was defined as grade 5 sudden death (not otherwise specified). Patients 6 was died due to the disease progression, however we could not deny the possibility of treatment-related death of patient 7 . We reported the independent data monitoring committees of this trial about these cases and they decided to continue this study with careful patient monitoring.

Immunological monitoring and clinical outcomes. Three patients $(6,8$ and 10$)$ terminated the protocol therapy at the

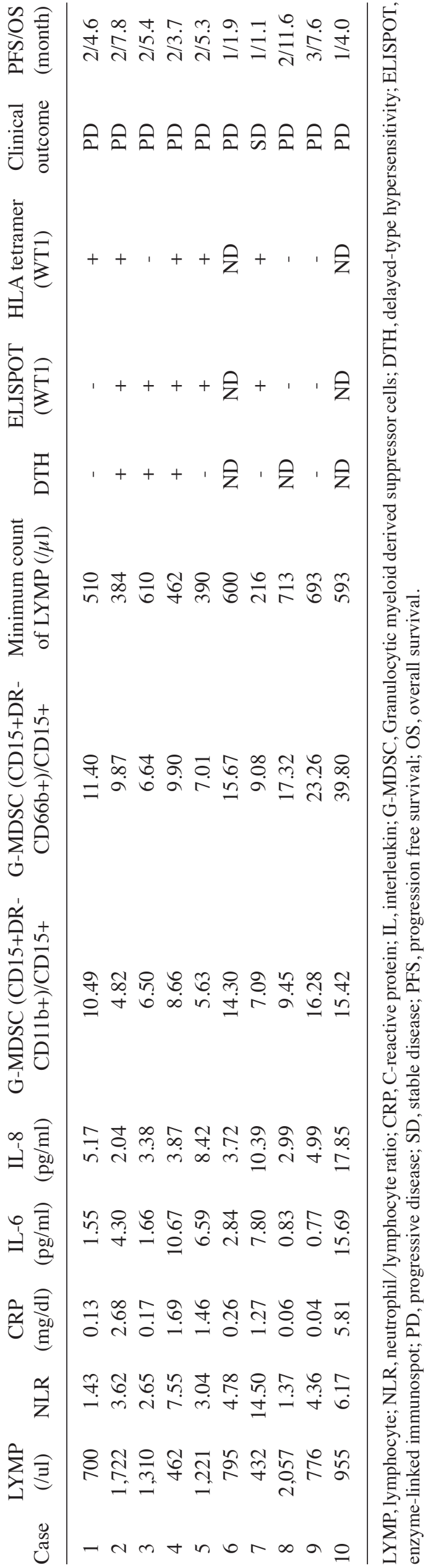



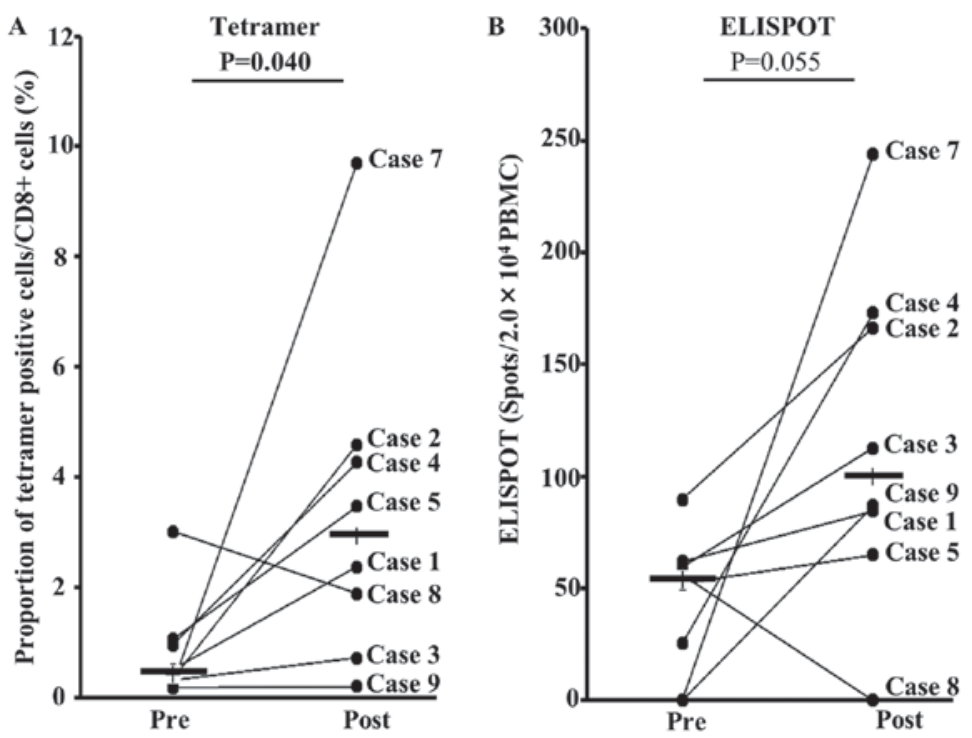

C

Case 7

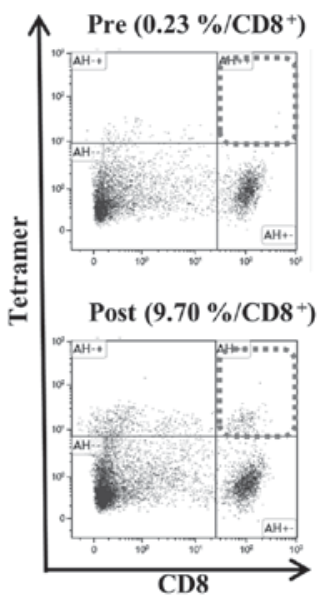

Figure 2. Tetramer and ELISPOT assays before and after vaccination. (A) Proportion of WT1-specific T-cells before and after vaccination in the tetramer assay. The proportion of WT1-specific cytotoxic T-lymphocytes is expressed as the percentage of $\mathrm{CD}^{+}$cells. The median is marked with thick horizontal lines. The proportion of WT1-specific cytotoxic T-lymphocytes increased significantly after vaccination $(\mathrm{P}=0.040)$. (B) Number of spots indicating IFN- $\gamma$ release by peripheral blood mononuclear cells (PBMCs) in response to WT1 peptide before and after vaccination using the ELISPOT assay. The median is marked with thick horizontal lines. The number of spots tended to increase but was not significantly higher after $\mathrm{DC}$ vaccination $(\mathrm{P}=0.055)$. (C) Tetramer staining of PBMCs obtained from case 7 before and after vaccination.
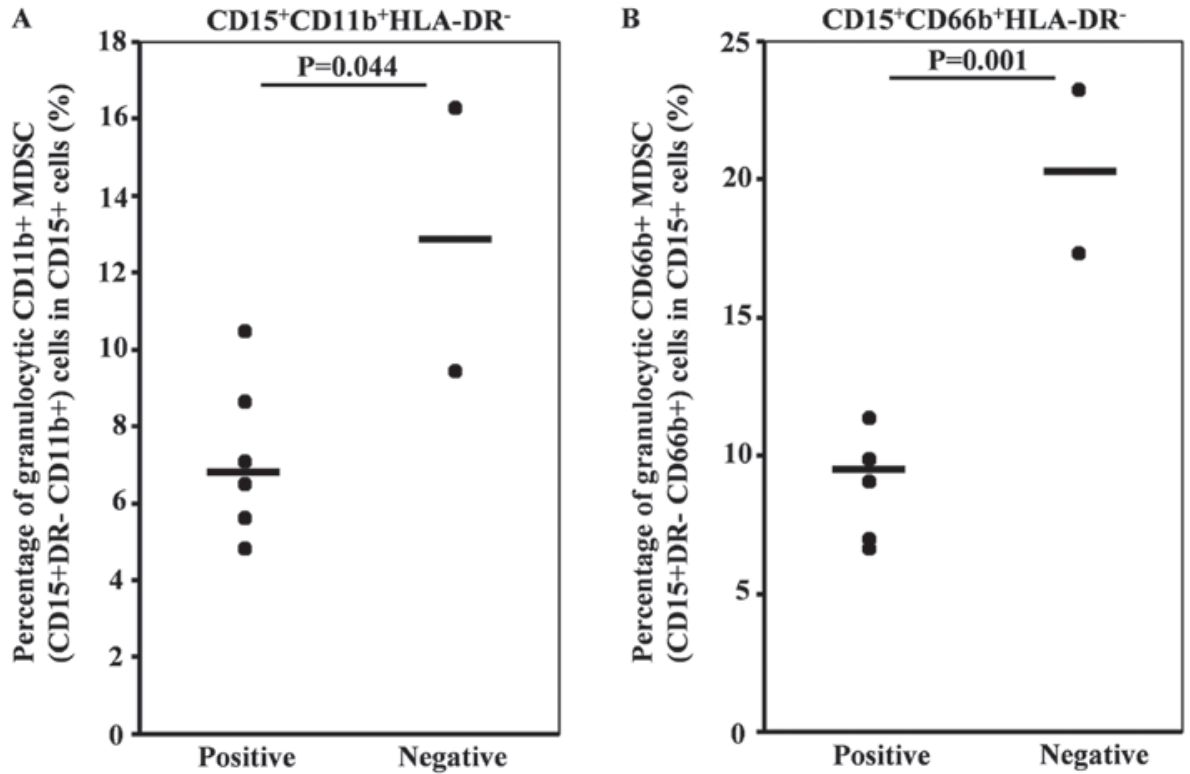

Figure 3. Correlation between positive immune response and low percentage of CD11 $\mathrm{b}^{+}$and $\mathrm{CD}_{6} 6 \mathrm{~b}^{+}$granulocytic myeloid derived suppressor cells (MDSCs) in $\mathrm{CD}_{15}{ }^{+}$cells. (A and B) Positive immune response (tetramer or ELISPOT) correlated significantly with a low percentage of $(\mathrm{A}) \mathrm{CD} 1 \mathrm{~b}^{+}(\mathrm{P}=0.044)$ and (B) $\mathrm{CD}_{66} \mathrm{~b}^{+}(\mathrm{P}=0.001)$ granulocytic MDSCs in $\mathrm{CD} 15^{+}$cells. The median is marked with thick horizontal lines.

first cycle. Thus, we could not check their immunological monitoring data after DC vaccination. Only patient 8 underwent an immunological monitoring blood test and CT scan, which revealed disease progression the same day. Finally, we analyzed the results of tetramer and ELISPOT assays for 8 patients and DTH for 7 patients. DCDOC elicited a WT1-specific response in 5 of the 8 patients as indicated by the HLA/WT1-tetramer assay (Table III). The proportion of HLA/WT1-tetramer-positive T-cells significantly increased after DC vaccination ( $\mathrm{P}=0.040$; Fig. $2 \mathrm{~A}$ ). Furthermore, the WT1-specific T-cell response was observed to be enhanced in
5 of the 8 patients according to the ELISPOT assay (Table III). The number of spots after DC vaccination tended to increase $(\mathrm{P}=0.055$; Fig. 2B).

To identify predictive factors for the immune response to DC vaccination, we checked the various cytokines and immune cell subsets in pretreatment peripheral blood by flow cytometry-based comprehensive leukocyte immunophenotyping. Positive immune response (tetramer or ELISPOT) positivity significantly correlated with a low percentage of $\mathrm{CD}_{11 b^{+}}$and $\mathrm{CD}_{6} 6 \mathrm{~b}^{+}$granulocytic myeloid-derived suppressor cells (MDSCs) in CD15+ cells (Fig. 3). However, 

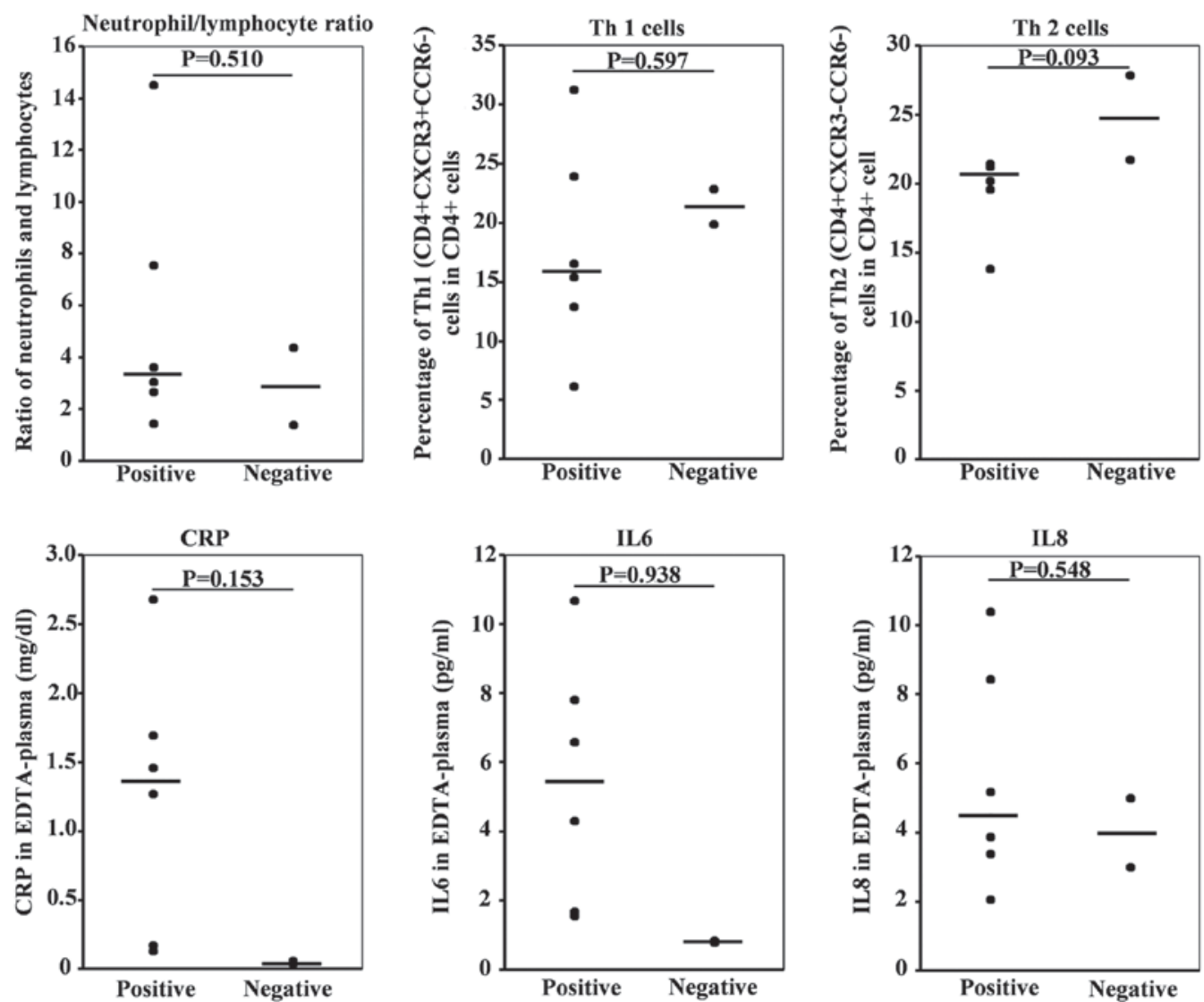

Figure 4. Pretreatment of various circulating lymphocyte phenotypes and cytokines. Positive immune response (tetramer or ELISPOT) did not correlate significantly with the neutrophil lymphocyte ratio; the percentages of Th1 $\left(\mathrm{CD} 4^{+} \mathrm{CXCR} 3^{+} \mathrm{CCR} 6\right)$ or $\mathrm{Th} 2\left(\mathrm{CD} 4^{+} \mathrm{CXCR} 3^{-} \mathrm{CCR} 6^{-}\right)$; $\mathrm{C}^{-r e a c t i v e}$ protein $(\mathrm{CRP})$, interleukin (IL)-6, and IL-8.

no differences in neutrophil lymphocyte ratio or percentages of Th1 $\left(\mathrm{CD} 4{ }^{+} \mathrm{CXCR}^{+} \mathrm{CCR} 6\right)$ ) or Th2 $\left(\mathrm{CD}^{+}{ }^{+} \mathrm{CXCR} 3^{+} \mathrm{CCR} 6\right)$, C-reactive protein (CRP), IL-6, and IL-8 were observed. (Fig. 4 and Table III).

\section{Discussion}

Safety of WT1 peptide-pulsed DCDOC. In this study, we could not evaluate the safety of WT1 peptide-pulsed DCDOC therapy for esophageal squamous cell cancer. Only 1 patient could complete the protocol therapy.

Five patients (50\%) had grade 3 or 4 neutropenia, and 1 patient had grade 3 febrile neutropenia. In an earlier report on single-agent docetaxel (docetaxel $70 \mathrm{mg} / \mathrm{m}^{2}$ every 21 days) for patients with metastatic esophageal cancer, grade 3 or 4 neutropenia was noted in 43 of 49 patients (88\%), and 9 of 49 patients (18\%) developed febrile neutropenia (14). In our study, we enrolled patients who had already received first-line chemotherapy or chemoradiotherapy; therefore, we decreased the docetaxel dose to $50 \mathrm{mg} / \mathrm{m}^{2}$ every 28 days. The rate of neutropenia in this study seemed tolerable. However, we could not determine if the docetaxel dose of $50 \mathrm{mg} / \mathrm{m}^{2}$ every 28 days was appropriate or not because, owing to disease progression, the protocol study failed in most patients.

Clinical effect of WT1 peptide-pulsed DCDOC for esophageal cancer. We could not observe the clinical effect of DCDOC therapy. Disease progression was observed in 9 patients, and 1 patient died during the second cycle of the protocol therapy. The median overall survival was 5 months (range 1.1-11.6).

In a previous study on single-agent docetaxel for patients with metastatic esophageal cancer, the response rates in patients with and without prior chemotherapy were reported to be $16 \%$ (6 of 38) and 36\% (4 of 11), respectively (14). Two reasons might explain the lack of a clinical response to DCDOC therapy. First, all patients had already received first-line chemotherapy (first-line chemotherapy, $\mathrm{N}=5$; second-line $\mathrm{N}=1$; third-line $\mathrm{N}=3$; fourth-line $\mathrm{N}=1$ ). Second, 7 of 10 patients had already received chemotherapy including docetaxel, which failed. We enrolled the patients who had already received docetaxel, because we expected immune enhancement effect of docetaxel in addition to the direct antitumor effect (15-17). Under these severe conditions, the antitumor effect of DCDOC therapy seems to be insufficient.

Immune response of esophageal cancer patients receiving WT1 peptide-pulsed DCDOC. An emerging avenue of clinical research in solid cancers is the use of immune-checkpoint inhibitors. Several checkpoint inhibitors, targeting multiple different checkpoints, have been developed; however, their efficacy is still not as expected. At the same time, DC-based immunotherapy has been receiving a lot of attention and is therefore being applied for treating various cancers (23). Nevertheless, only a few studies have reported on DC-based 
immunotherapy for esophageal cancer, and none demonstrated a clinical response (24-27). Narita et al (25), performed a phase I/II clinical trial of monocyte-derived DCs pulsed with SART1 peptide in 7 patients with advanced esophageal cancer. The effectiveness was not clearly confirmed; however, in vitro studies revealed that DCs generated for this therapy possessed a potent ability of inducing SART1 peptide-specific CTLs (25). The most important result in this study was that DCDOC elicited a WT1-specific response in 6 of the 8 patients as detected by the HLA/WT1-tetramer or ELISPOT assay, regardless of the myelosuppression associated with docetaxel. To our knowledge, this is the first report of immune response induced by DCDOC in esophageal squamous cell cancer. We previously conducted a pilot study of WT1 peptide (DCGEM) as first-line therapy in chemo-naive pancreatic cancer patients with local advancement or metastasis (12). In that study, the disease control rate and median overall survival were $60 \%$ and 243 days, respectively, which are promising. Furthermore, we observed fewer adverse effects compared with gemcitabine in combination with nab-paclitaxel or $\mathrm{S}-1$. Koido et al reported that the combined treatment of chemotherapy and DCs pulsed with a mixture of 3 types of WT1 peptides, including both MHC class I and II-restricted epitopes, induced WT1-CTLs during long-term vaccination and may be associated with disease stability in advanced pancreatic cancer (28). On the basis of these reports and our present results, we believe that WT1 peptide-pulsed DC vaccination might be an effective therapy for esophageal cancer, either alone or in combination with other immunotherapy approaches, such as immune-checkpoint inhibitors.

Patient selection is important for effective immunotherapy development. To this end, we evaluated various immunological biomarkers in our patients before treatment. We found that positive immune response had significant relevance to the low percentage of $\mathrm{CD}_{11 b^{+}}$and $\mathrm{CD} 6 \mathrm{~b}^{+}$ granulocytic myeloid derived suppressor cells (MDSCs) in $\mathrm{CD} 15^{+}$cells.

One of the reasons why we failed to observe a clinical effect was the huge tumor burden. Lee et al described a phase I/IIa trial of adjuvant immunotherapy with tumor antigen-pulsed DCs for patients with hepatocellular carcinoma. They reported that the median time to progression was 11.8 months in the control group and 36.6 months in the DC-vaccination group (29). In addition dysfunction of vaccine-induced $\mathrm{T}$ cells might be another reason. The tetramer staining results of some patients are not consistent with the ELISPOT assay (Fig. 2). It indicates that certain percentage of tetramer-positive $\mathrm{T}$ cells is not functional. We would like to examine the correlation between dysfunction of vaccine-induced T cells and PD1 expression level in the future experiment. If high PD1 expression is correlated with dysfunction of vaccine-induced $\mathrm{T}$ cells, PD-1 blockade therapy may be combined to enhance the cytolytic activity. Nevertheless, we believe that our protocol study had an antitumor effect towards esophageal squamous cell carcinoma.

We report that DCDOC elicited a WT1-specific immune response regardless of the myelosuppression associated with docetaxel. In future studies, we plan to assess DCDOC as an adjuvant therapy for esophageal cancer.

\section{Acknowledgements}

Not applicable.

\section{Funding}

This study was supported in part by Grants-in-Aid for Scientific Research from the Japan Society for Promotion of Science (26221005); a Project for Development of Innovative Research on Cancer Therapeutics (P-Direct) and the Project for Cancer Research And Therapeutic Evolution (P-CREATE) from Japan Agency for Medical Research and Development (AMED); The Tokyo Biochemical Research Foundation to Yutaka Kawakami; and tella Inc., Tokyo, to Yuko Kitagawa, Masato Okamoto, and Yutaka Kawakami. This clinical trial was performed partly by the research fund from Tella, Inc. However, Tella, Inc. was not involved in any of this study, including the study design, patient treatement, clinical and immunological evaluation, and paper writing. Tella, Inc, does not have benefit from the results of this study.

\section{Availability of data and materials}

All data generated or analyzed during this study are included in this published article.

\section{Authors' contributions}

HT, YKa, TM, SM, TS, TF, MO, MS and YKi planned the project. HT, YKa, MS and YKi supervised the project. HT, TM, EB, SM, HH, JT, YH, HT, HK and YKi enrolled the patients. TS, TF and MO conducted the experiments. TM, EB, TS, TF and MO analyzed the data. HT, YKa and TM drafted and wrote the manuscript. All authors read and approved the final manuscript.

\section{Ethics approval and consent to participate}

The institutional review board of Keio University approved the study (Approval number 2011153), and all patients provided written informed consent. This clinical trial was registered in the University Hospital Medical Information Network (UMIN) Clinical Trials Registry, number UMIN000006704.

\section{Consent for publication}

All patients provided written informed consent for the publication of any associated data.

\section{Competing interests}

Professor Masato Okamoto is a stockholder in tella Inc. and a former Director of the Board for Science and Medicine. Professor Yuko Kitagawa, Professor Masato Okamoto and Professor Yutaka Kawakami received research funding from tella Inc.

\section{References}

1. Pennathur A, Gibson MK, Jobe BA and Luketich JD: Oesophageal carcinoma. Lancet 381: 400-412, 2013. 
2. Enzinger PC and Mayer RJ: Esophageal cancer. N Engl J Med 349: 2241-2252, 2003.

3. Paul S and Altorki N: Induction therapy for esophageal cancer. Thorac Surg Clin 23: 499-507, 2013.

4. Sukari A,Nagasaka M,Al-Hadidi A and LumLG: Cancer Immunology and Immunotherapy. Anticancer Res 36: 5593-5606, 2016.

5. Palucka K and Banchereau J: Cancer immunotherapy via dendritic cells. Nat Rev Cancer 12: 265-277, 2012.

6. Kantoff PW, Higano CS, Shore ND, Berger ER, Small EJ, Penson DF, Redfern CH, Ferrari AC, Dreicer R, Sims RB, et al: Sipuleucel-T immunotherapy for castration-resistant prostate cancer. N Engl J Med 363: 411-422, 2010.

7. Cheever MA, Allison JP, Ferris AS, Finn OJ, Hastings BM, Hecht TT, Mellman I, Prindiville SA, Viner JL, Weiner LM and Matrisian LM: The prioritization of cancer antigens: A national cancer institute pilot project for the acceleration of translational research. Clin Cancer Res 15: 5323-5337, 2009.

8. Oji Y, Yano M, Nakano Y, Abeno S, Nakatsuka S, Ikeba A, Yasuda T, Fujiwara Y, Takiguchi S, Yamamoto $\mathrm{H}$, et al: Overexpression of the Wilms' tumor gene WT1 in esophageal cancer. Anticancer Res 24: 3103-3108, 2004.

9. Miyatake T, Ueda Y, Morimoto A, Enomoto T, Nishida S, Shirakata T, Oka Y, Tsuboi A, Oji Y, Hosen N, et al: WT1 peptide immunotherapy for gynecologic malignancies resistant to conventional therapies: A phase II trial. J Cancer Res Clin Oncol 139: 457-463, 2013.

10. Ohno S, Okuyama R, Aruga A, Sugiyama H and Yamamoto M Phase I trial of Wilms' tumor 1 (WT1) peptide vaccine with GM-CSF or CpG in patients with solid malignancy. Anticancer Res 32: 2263-2269, 2012.

11. Tsuboi A, Oka Y, Udaka K, Murakami M, Masuda T, Nakano A, Nakajima H, Yasukawa M, Hiraki A, Oji Y, et al: Enhanced induction of human WT1-specific cytotoxic T lymphocytes with a 9-mer WT1 peptide modified at HLA-A*2402-binding residues. Cancer Immunol Immunother 51: 614-620, 2002.

12. Mayanagi S, Kitago M, Sakurai T, Matsuda T, Fujita T, Higuchi H, Taguchi J, Takeuchi H, Itano O, Aiura K, et al: Phase I pilot study of Wilms tumor gene 1 peptide-pulsed dendritic cell vaccination combined with gemcitabine in pancreatic cancer. Cancer Sci 106: 397-406, 2015

13. Kuwano H, Nishimura Y, Oyama T, Kato H, Kitagawa Y, Kusano M, Shimada H, Takiuchi H, Toh Y, Doki Y, et al: Guidelines for diagnosis and treatment of carcinoma of the esophagus April 2012 edited by the Japan esophageal society. Esophagus 12: 1-30, 2015.

14. Muro K, Hamaguchi T, Ohtsu A, Boku N, Chin K, Hyodo I, Fujita $\mathrm{H}$, Takiyama $\mathrm{W}$ and Ohtsu T: A phase II study of single-agent docetaxel in patients with metastatic esophageal cancer. Ann Oncol 15: 955-959, 2004.

15. Garnett CT, Schlom J and Hodge JW: Combination of docetaxel and recombinant vaccine enhances T-cell responses and antitumor activity: Effects of docetaxel on immune enhancement. Clin Cancer Res 14: 3536-3544, 2008

16. Sundstedt A, Celander M, Ohman MW, Forsberg G and Hedlund G: Immunotherapy with tumor-targeted superantigens (TTS) in combination with docetaxel results in synergistic anti-tumor effects. Int Immunopharmacol 9: 1063-1070, 2009.

17. Kodumudi KN, Woan K, Gilvary DL, Sahakian E, Wei S and Djeu JY: A novel chemoimmunomodulating property of docetaxel: Suppression of myeloid-derived suppressor cells in tumor bearers. Clin Cancer Res 16: 4583-4594, 2010.
18. Eisenhauer EA, Therasse P, Bogaerts J, Schwartz LH, Sargent D, Ford R, Dancey J, Arbuck S, Gwyther S, Mooney M, et al: New response evaluation criteria in solid tumours: Revised RECIST guideline (version 1.1). Eur J Cancer 45: 228-247, 2009.

19. Kimura Y, Tsukada J, Tomoda T, Takahashi H, Imai K, Shimamura K, Sunamura M, Yonemitsu Y, Shimodaira S, Koido S, et al: Clinical and immunologic evaluation of dendritic cell-based immunotherapy in combination with gemcitabine and/or S-1 in patients with advanced pancreatic carcinoma. Pancreas 41: 195-205, 2012.

20. Figdor CG, de Vries IJ, Lesterhuis WJ and Melief CJ: Dendritic cell immunotherapy: Mapping the way. Nat Med 10: 475-480, 2004

21. Ohnishi M, Sakurai T, Heike Y, Yamazaki R, Kanda Y, Takaue Y, Mizoguchi $\mathrm{H}$ and Kawakami Y: Evaluation of cytomegalovirus-specific T-cell reconstitution in patients after various allogeneic haematopoietic stem cell transplantation using interferon-gamma-enzyme-linked immunospot and human leucocyte antigen tetramer assays with an immunodominant T-cell epitope. Br J Haematol 131: 472-479, 2005.

22. Kuwana M, Okazaki Y, Kaburaki J and Ikeda Y: Detection of circulating B cells secreting platelet-specific autoantibody is useful in the diagnosis of autoimmune thrombocytopenia. Am J Med 114: 322-325, 2003.

23. Palucka $\mathrm{K}$ and Banchereau J: Cancer immunotherapy via dendritic cells. Nat Rev Cancer 12: 265-277, 2012.

24. Liu X, Song N, Liu Y, Liu Y, Li J, Ding J and Tong Z: Efficient induction of anti-tumor immune response in esophageal squamous cell carcinoma via dendritic cells expressing MAGE-A3 and CALR antigens. Cell Immunol 295: 77-82, 2015.

25. Narita M, Kanda T, Abe T, Uchiyama T, Iwafuchi M, Zheng Z, Liu A, Kaifu T, Kosugi S, Minagawa M, et al: Immune responses in patients with esophageal cancer treated with SART1 peptide-pulsed dendritic cell vaccine. Int J Oncol 46: 1699-1709, 2015.

26. Forghanifard MM, Gholamin M, Moaven O, Farshchian M, Ghahraman M, Aledavood A and Abbaszadegan MR: Neoantigen in esophageal squamous cell carcinoma for dendritic cell-based cancer vaccine development. Med Oncol 31: 191, 2014.

27. Fujiwara S, Wada H, Miyata H, Kawada J, Kawabata R, Nishikawa H, Gnjatic S, Sedrak C, Sato E, Nakamura Y, et al: Clinical trial of the intratumoral administration of labeled DC combined with systemic chemotherapy for esophageal cancer. J Immunother 35: 513-521, 2012.

28. Koido S, Homma S, Okamoto M, Takakura K, Mori M, Yoshizaki S, Tsukinaga S, Odahara S, Koyama S, Imazu H, et al: Treatment with chemotherapy and dendritic cells pulsed with multiple Wilms tumor 1 (WT1)-specific MHC class I/II-restricted epitopes for pancreatic cancer. Clin Cancer Res 20: 4228-4239, 2014.

29. Lee JH, Lee Y, Lee M, Heo MK, Song JS, Kim KH, Lee H, Yi NJ, Lee KW, Suh KS, et al: A phase I/IIa study of adjuvant immunotherapy with tumour antigen-pulsed dendritic cells in patients with hepatocellular carcinoma. Br J Cancer 113: 1666-1676, 2015 